\title{
SURFACE COLOUR CHANGE IN WOOD DURING DRYING ABOVE AND BELOW FIBRE SATURATION POINT
}

\author{
M. C. McCurdy', S. Pang ${ }^{2}$, R. B. Keey
}

\begin{abstract}
A technique, useful for studying the formation of kiln brown stain in wood drying, has been developed to measure the surface colour change in a single board wood sample during drying. The wood sample is planed carefully in the green state to remove any surface wood that was damaged during cutting. The intact tracheids at the surface cause the evaporative front to remain at the surface during drying and therefore colour formation also occurs right at the surface. In this way, the colour can be measured using a spectrophotometer at various stages during drying without having to slice the sample.

Experiments were carried out to measure the change in colour of wood from green to EMC corresponding to the drying schedule used. At the end of each schedule the boards were held at the EMC to determine how the colour changed below fibre saturation point. The results show that the colour of the wood continues to change below the fibre saturation point and the nature of the colour change indicates an increase in the complexity of the coloured compounds present.

Further experiments were done to measure the rate of colour development at different temperatures using the technique developed. The results have shown a correlation between temperature and colour development over the range $50^{\circ} \mathrm{C}$ to $70^{\circ} \mathrm{C}$ with the rate increasing significantly above $60^{\circ} \mathrm{C}$.
\end{abstract}

Keywords: kiln brown stain, wood colour, colour measurement, wood drying.

\section{INTRODUCTION}

Pinus radiata is known for its bright colour, clear ring pattern and medium strength which make it suitable to a wide variety of end uses such as panelling, mouldings, joinery and furniture. However, wood colour changes during drying when high temperature schedules are employed which adversely affects its reputation. This colour change can be in the form of an overall change in colour or the formation of kiln brown stain (McCurdy et. al., 2003). Kiln brown stain has the greater effect on quality for high value appearance products. This is an irregular brown colouration that occurs 1 to $2 \mathrm{~mm}$ near the surface of drying boards that is considerably darker than the surrounding wood. This layer is consistent with the thin dry layer formed in the kiln drying of softwood lumber (Pang et al., 1994).

Studies by McDonald et al (2000) have shown that kiln brown stain in Pinus radiata is most likely caused by a Maillard reaction between sugars and amino acids in the wood sap as it is concentrated at the wood surface during drying.

\footnotetext{
${ }^{1,2,3}$ Wood Technology Research Centre, Department of Chemical and Process Engineering, University of Canterbury, Private Bag 4800, Christchurch, New Zealand.

${ }^{2}$ Corresponding author: shusheng.pang@canterbury.ac.nz Received: December 14, 2005. Accepted: April 07, 2006
} 
Various methods have been developed to measure kiln brown stain formation in samples of wood during drying. Studies by Kreber and Haslett (1997) used visual inspection to determine the level of stain whereas Dawson et. al. (2003) used a colorimeter for the same purpose. More recently, Ledig and Seyfarth (2001) have used a spectrophotometer to measure surface colour in European beech and have successfully characterised the wood colour using the CIELab system. Photographic techniques (McCurdy et.al., 2001; Dieste, 2002) and microscopic techniques (McCurdy et.al., 2005) have also been developed that combine digital photography with computer image analysis.

The major difficulty encountered when measuring kiln brown stain is that the most significant stain formation occurs about $1 \mathrm{~mm}$ below the surface of the timber. This means that any measurement of the surface may not measure the full extent of the stain formed. Also if the surface is removed to reveal the stain it is a destructive test so cannot be performed while the sample is being dried in the kiln. This paper describes a technique developed to overcome this problem and results from initial experiments to determine colour change rates will be discussed.

\section{MATERIALS AND METHODS}

The samples used were cut from green Pinus radiata boards to a size of $25 \times 25 \times 100 \mathrm{~mm}$. The ends and two of the sides of the samples were sealed with paint so that only the top and bottom flat faces (tangential) were available for evaporation of moisture. Then, the samples were stored in a freezer until further processing for the drying tests.

Immediately before drying, the surfaces of the samples were prepared by carefully smoothing them with a hand plane. The objective of this step was to remove the damaged layer from the surface of the wood gently so that there are intact tracheids near the surface. The advantage of planing the surface is that the blade slices through the wood which gives a smoother finish and causes less damage to the cells on the surface.

The surface to be measured was marked at sampling areas before drying commenced so that the parts of the surface measured were consistent the same throughout the drying process. This was done by marking each point with a circle slightly larger than the aperture of the spectrophotometer. In the experiments conducted, four measurement points were used for each sample.

The measurement of the surface colour during drying was performed by removing the sample from the dryer, recording the time and weight. The colour of each of the measurement points was then determined using a surface reflectance spectrophotometer (Minolta CM-2500d portable integrating sphere spectrophotometer). This instrument uses two pulsed xenon lamps as a light source, a diffraction grating for spectral separation and a silicon photodiode array as the light-receiving element. This array is a dual 40element device that can measure at $10 \mathrm{~nm}$ intervals over the range from $400 \mathrm{~nm}$ to $700 \mathrm{~nm}$.

In addition a photograph was also taken of the surface each time when the colour was measured for qualitative analysis of the colour development. The entire measurement process only took a few minutes, thus keeping the cooling and drying of the sample outside the dryer to a minimum.

The results presented in this paper are from seven drying runs, the first three of which were performed to test the technique and determine if colour development changes below fibre saturation point. The remaining four drying runs, and one of the previous runs (initial run 3 is the same as rate run 5) were used to determine the rate of colour development during drying at different drying temperatures. In each of the drying runs the samples were brought to a moisture content of approximately $0.2 \mathrm{~kg} / \mathrm{kg}$ at each schedule and then the sample was held without further drying or condensing for 36-48h. This was achieved by controlling the EMC at approximately $0.2 \mathrm{~kg} / \mathrm{kg}$ at different dry-bulb temperatures. The conditions used for each run are shown in Table 1 below. 
Table 1. Drying schedules and holding conditions for the eight drying runs.

\begin{tabular}{|l|l|l|l|l|l|l|}
\hline \multirow{2}{*}{ Run No. } & \multicolumn{3}{|l|}{ Drying conditions } & \multicolumn{3}{l}{ Holding conditions } \\
\cline { 2 - 7 } & Dry bulb & Wet bulb & $\begin{array}{l}\text { Elapsed } \\
\text { time (h) }\end{array}$ & Dry bulb & Wet bulb & $\begin{array}{l}\text { Elapsed } \\
\text { time (h) }\end{array}$ \\
\hline Initial Run 1 & $50^{\circ} \mathrm{C}$ & $40^{\circ} \mathrm{C}$ & 48 & $50^{\circ} \mathrm{C}$ & $48^{\circ} \mathrm{C}$ & 50 \\
\hline Initial Run 2 & $70^{\circ} \mathrm{C}$ & $60^{\circ} \mathrm{C}$ & 48 & $70^{\circ} \mathrm{C}$ & $69^{\circ} \mathrm{C}$ & 26 \\
\hline Initial Run $3 *$ & $50^{\circ} \mathrm{C}$ & $40^{\circ} \mathrm{C}$ & 75 & $70^{\circ} \mathrm{C}$ & $69^{\circ} \mathrm{C}$ & 48 \\
\hline Rate Run 1 & $50^{\circ} \mathrm{C}$ & $30^{\circ} \mathrm{C}$ & 48 & $50^{\circ} \mathrm{C}$ & $49^{\circ} \mathrm{C}$ & 36 \\
\hline Rate Run 2 & $50^{\circ} \mathrm{C}$ & $30^{\circ} \mathrm{C}$ & 48 & $55^{\circ} \mathrm{C}$ & $54^{\circ} \mathrm{C}$ & 36 \\
\hline Rate Run 3 & $50^{\circ} \mathrm{C}$ & $30^{\circ} \mathrm{C}$ & 48 & $60^{\circ} \mathrm{C}$ & $59^{\circ} \mathrm{C}$ & 36 \\
\hline Rate Run 4 & $50^{\circ} \mathrm{C}$ & $30^{\circ} \mathrm{C}$ & 48 & $65^{\circ} \mathrm{C}$ & $64^{\circ} \mathrm{C}$ & 36 \\
\hline Rate Run $5^{*}$ & $50^{\circ} \mathrm{C}$ & $40^{\circ} \mathrm{C}$ & 75 & $70^{\circ} \mathrm{C}$ & $69^{\circ} \mathrm{C}$ & 48 \\
\hline
\end{tabular}

* These are the same run.

\section{RESULTS AND DISCUSSION}

The spectrophotometer measurements produced a spectrum for each area measured at different drying times as well as the colour expressed using the CIELab colour coordinates L*, a* and $\mathrm{b}^{*}$. From the colour coordinates, the colour change was then calculated $(\Delta \mathrm{E})$ using the following equation, which represent the overall change in colour:

$$
\Delta E=\sqrt{\Delta L^{2}+\Delta a^{2}+\Delta b^{2}}
$$

The time point with the greatest value for lightness was chosen as the datum with which the change in wood colour was compared. This point occurred within a few hours of drying when the surfaces of the samples had dried out but discolouration had not begun. The $\Delta \mathrm{E}$ values calculated for each run have been plotted in Figure 1 to Figure 3, with the moisture content also plotted on these graphs.

The results for the Initial Run 1 (Figure 1) show that the colour change drops sharply at the beginning of drying, as the wood colour gets lighter due to the surface losing moisture. After reaching peak lightness at about $5 \mathrm{~h}$ into the schedule the surface colour of the sample darkens in an approximately linear relationship with elapsed time. There appears to be a slight change in the slope at $72 \mathrm{~h}$ when the schedule was changed to holding conditions to maintain the moisture content.

The results for the Initial Run 2 (Figure 2) show a similar increase in lightness at the beginning of drying. However, the colour change beyond this point was not in linear relationship with elapsed time as found in the first run. The colour change was approaching an asymptotic value with a much higher value. At $48 \mathrm{~h}$ when the schedule was changed to hold the moisture content the wood colour seems to keep changing at a constant rate. 
The results for the Initial Run 3 (Figure 3) also show a sharp increase in lightness when the surface begins drying. This is followed by a slow increase in colour, up to the point where the schedule is changed to the holding conditions at 78 hours. At this point the colour change increases sharply and then gradually decreases when the colour change appears to tend toward an asymptotic value in a similar way to the Initial Run 2.

The subtraction spectra for the Initial Run 3 are plotted in Figure 4. These spectra were obtained by subtracting the $4 \mathrm{~h}$ spectra from the spectra of each measurement after $4 \mathrm{~h}$. This means that the higher the absorbance value of light at a particular wavelength the darker the colour. The spectra show that as drying progresses there is an overall increase in light absorption across all wavelengths. As drying progresses there was also a shift to a higher wavelength of peak (red shift).

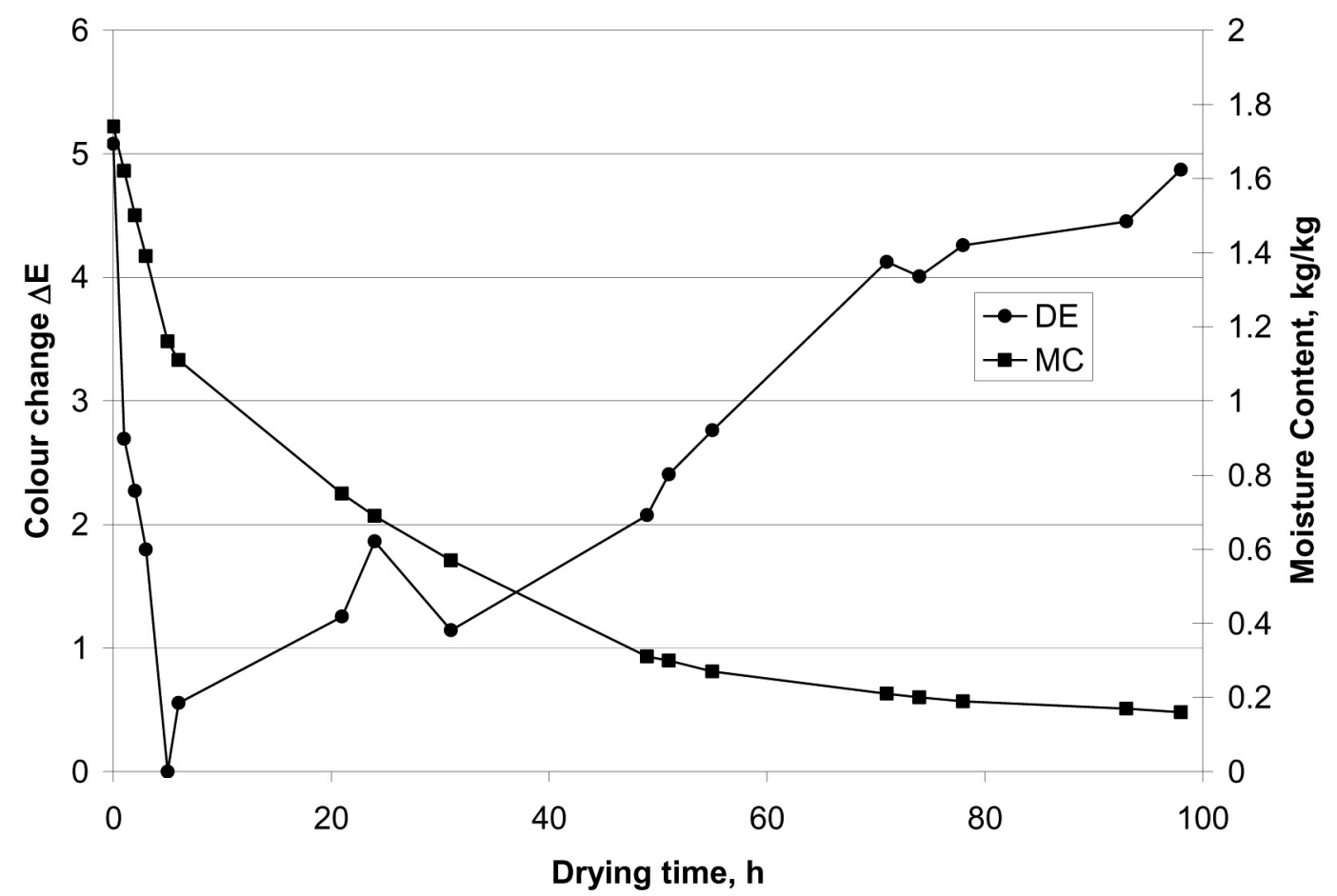

Figure 1. Results for Initial Run 1 showing the change in colour $(\Delta \mathrm{E})$ and moisture content $(\mathrm{MC})$ as a function of elapsed time. 


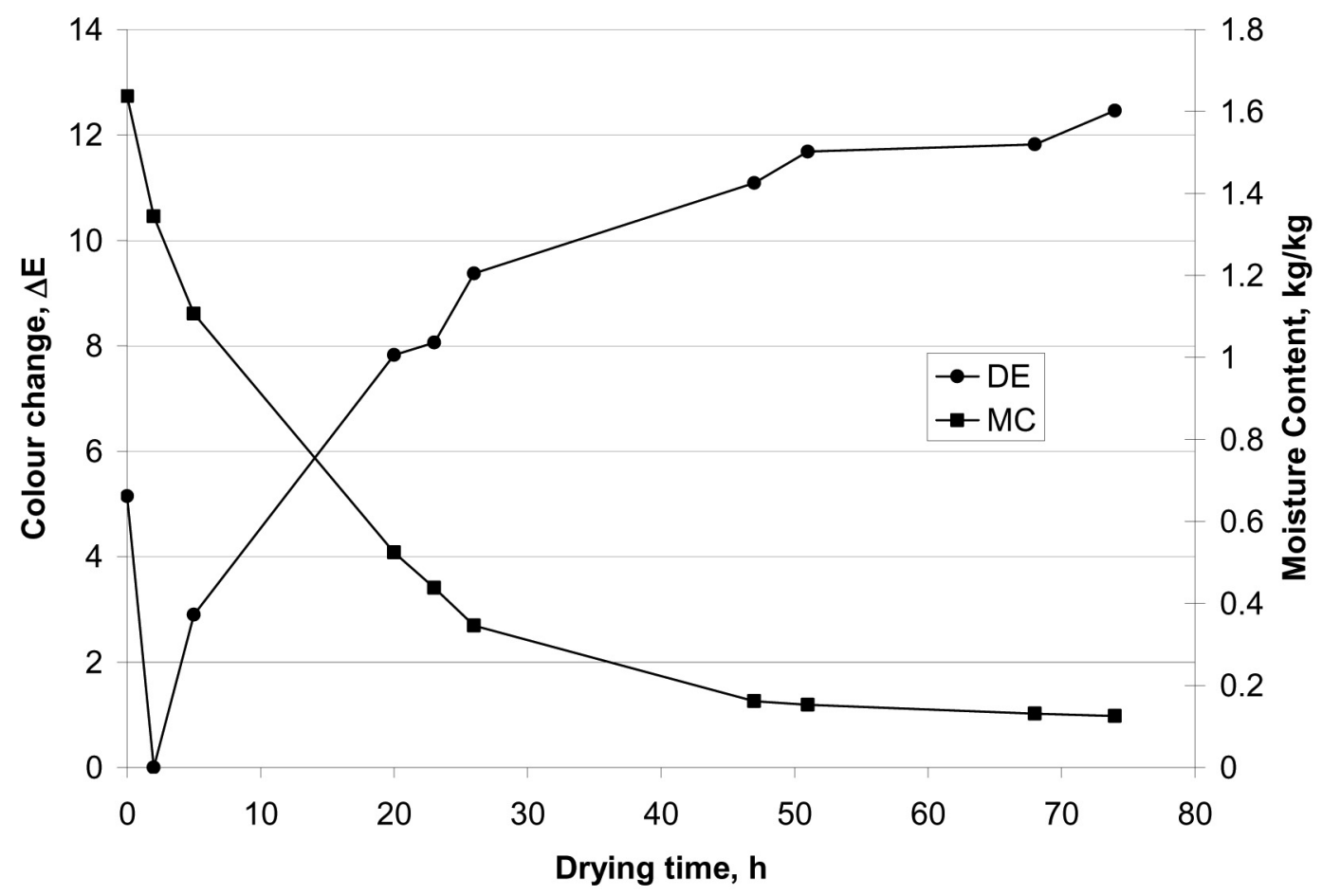

Figure 2. Results for Initial Run 2 showing the change in colour $(\Delta \mathrm{E})$ and moisture content $(\mathrm{MC})$ as a function of elapsed time.

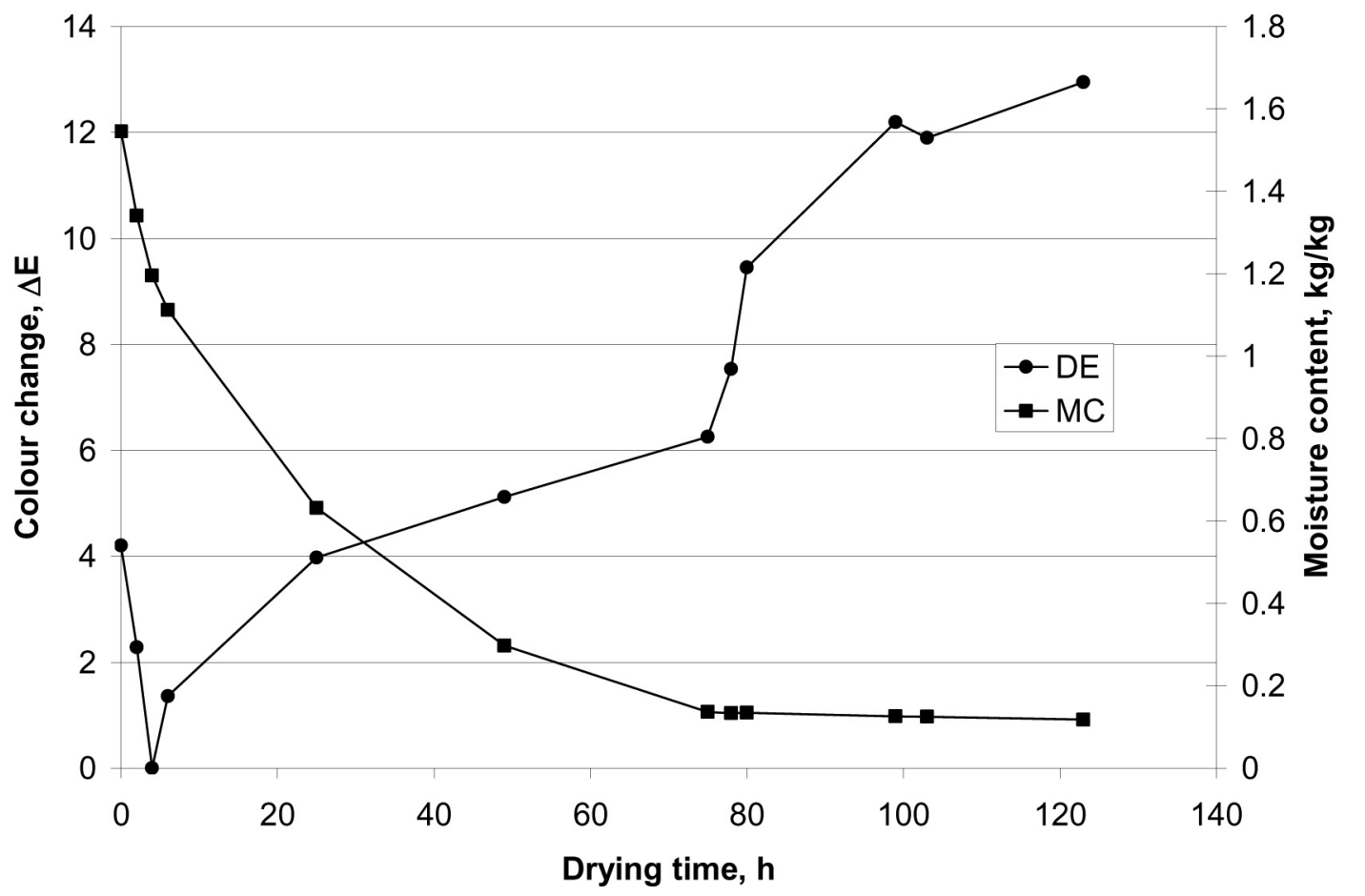

Figure 3. Results for Initial Run 3 showing the change in colour $\triangle \mathrm{E}$ ) and moisture content (MC) as a function of elapsed time. 


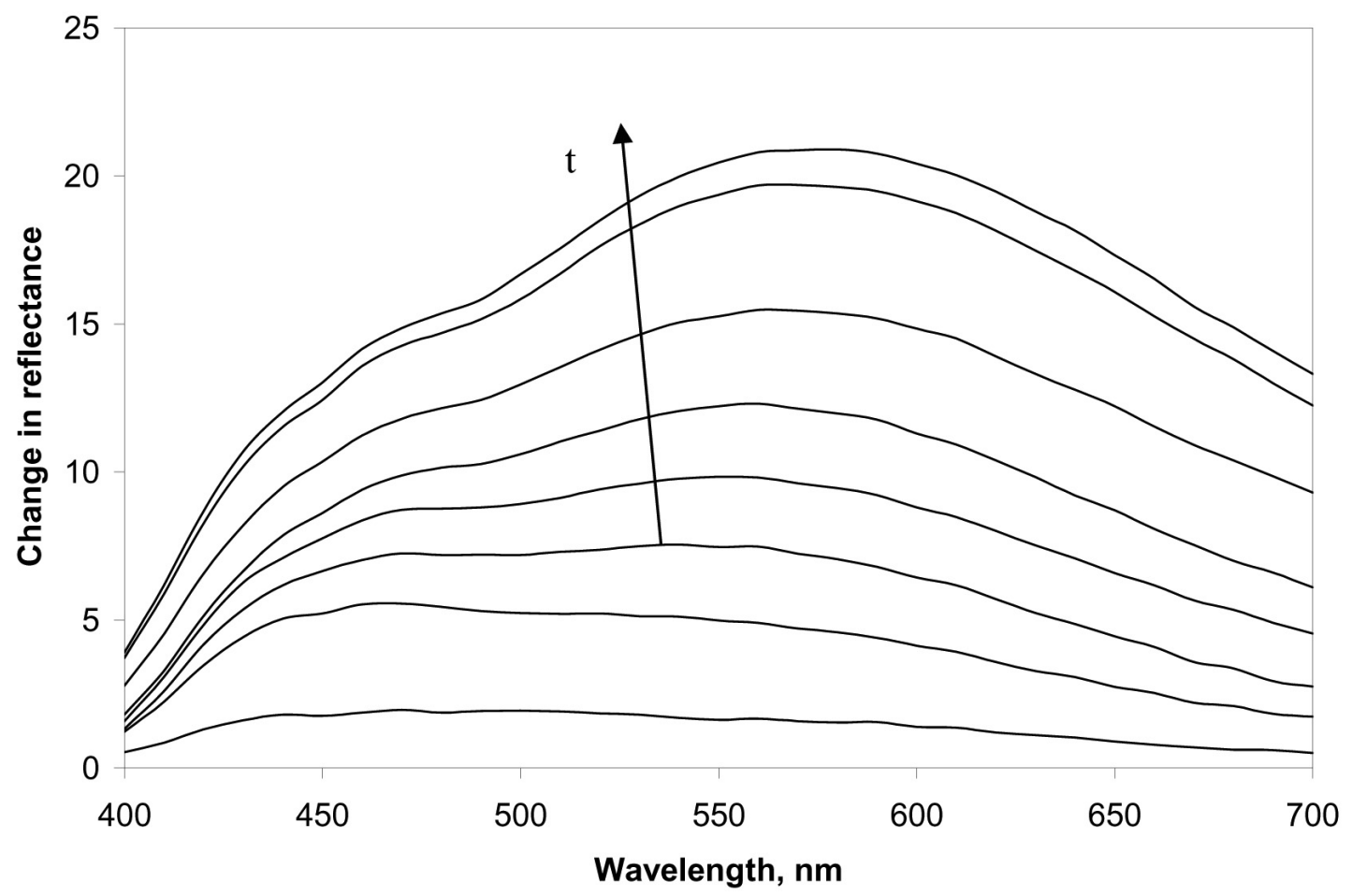

Figure4. Subtraction spectra for Initial Run 3 with the values showing spectra of each measurements after 4 hours being subtracted by the spectrum at 4 hours.

The results for the rate determination experiments (Rate Runs 1 -5) are arranged to plot the colour change in the approximately linear region as a function of elapsed time as shown in Figure 5. These data are generally a good linear fit except for the $70^{\circ} \mathrm{C}$ data (too few data points).

Most importantly, the rate of colour change clearly shows an increase with drying temperature. In order to quantify the relationship between the temperature of the drying schedule and the rate of colour changes, the colour change rates for all of the runs are plotted in Figure 6. It has been found that such relationship was non-linear for the data produced by this experiment and could only be fitted by a $4^{\text {th }}$ order polynomial. This may be an error in the experiment or may be an accurate representation of colour change in wood. The plot shows that the colour change rate increases remarkably between $65^{\circ} \mathrm{C}(338 \mathrm{~K})$ and $70^{\circ} \mathrm{C}$ $(343 \mathrm{~K})$. The data could not be fitted using the Arrhenius equation. 


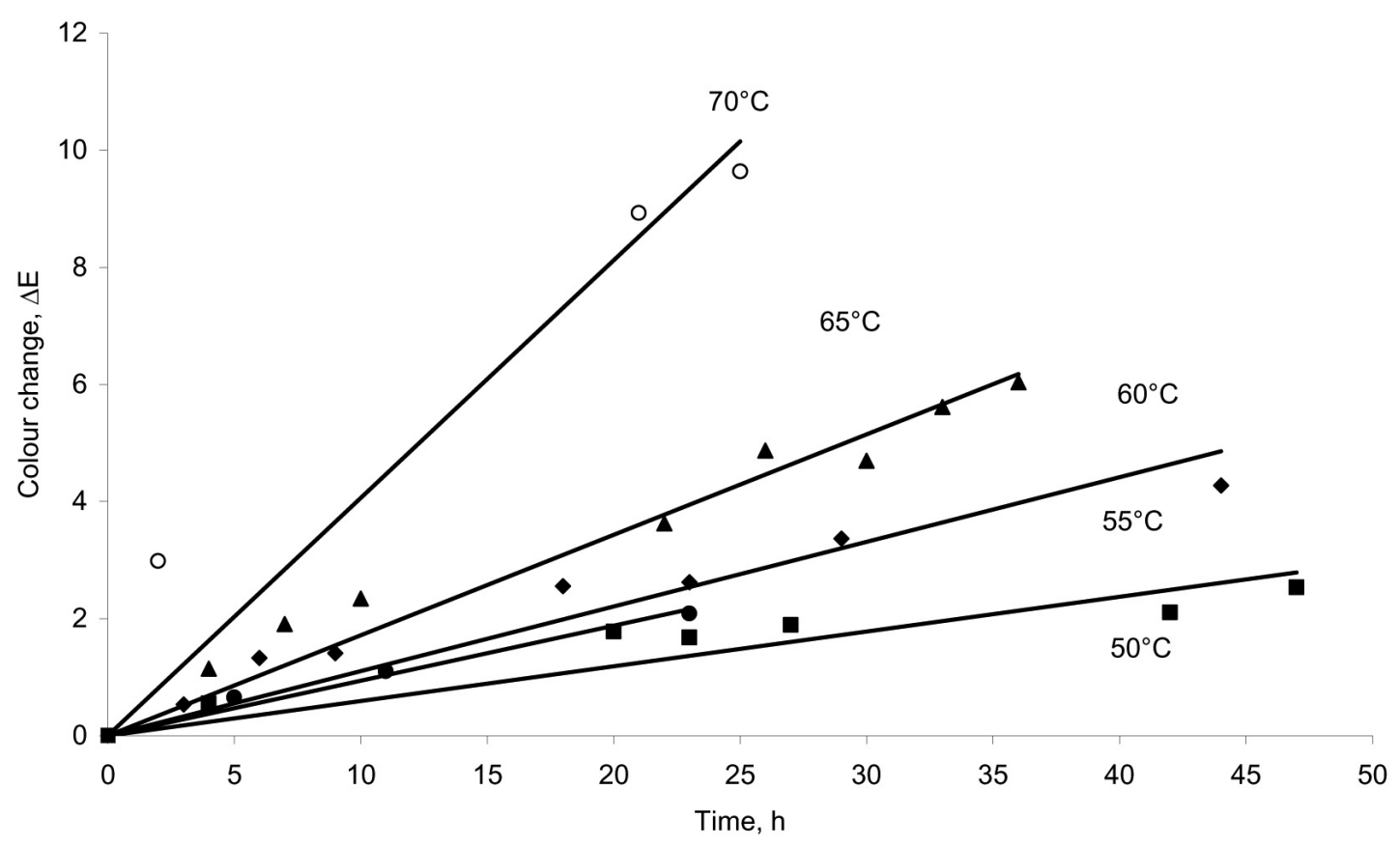

Figure 5. Colour change with time for 5 different drying temperatures.

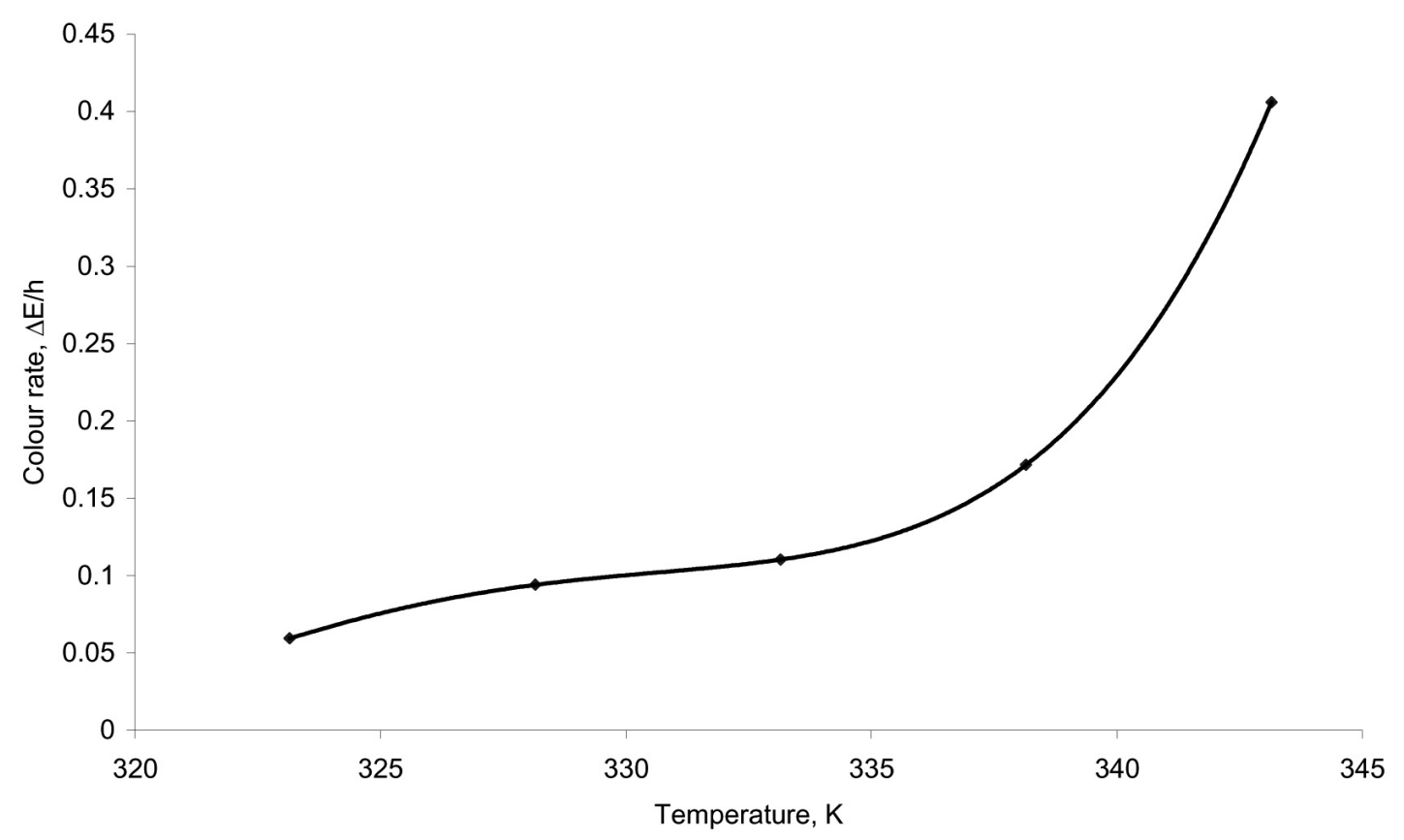

Figure 6. Plot of colour change rate with temperature for Pinus radiata dried at 5 different temperatures. 
From the results described above, it was observed that in the (Rate Run 1 and 2) Initial Run 2 drying run at first seem to suggest that there was a reduction in the rate of colour development as moisture content decreases. The results from the Initial 3 run however show that the higher rate of colour development caused by the increase in temperature from the drying schedule to the holding schedule was not affected by the moisture content. This means that there must be another explanation for the change in rate of colour development.

The alternative explanation is that there is a maximum possible colour development caused by initial reaction of sap compounds based on the concentration of these compounds in the board before drying. Once these compounds have reacted, further reactions become more complex and proceed at a slower rate. The early stages of the Maillard reaction are reasonably well understood, but beyond the first (Amadori) products there are a large number of possible reactions (Fayle and Gerrard, 2002a), so it is difficult to imagine the actual structure of the coloured compounds produced.

The shift towards more complex reactions is supported by the shift to higher wavelengths in the subtraction spectra. The colour exhibited by the Maillard reaction products is most likely caused by a combination of extended polyene structures attached to electron-donor and -acceptor groups as is the case with most organic colorants (Nassau, 2001). The addition of more conjugated double bonds or donor-acceptor groups will cause the reaction products to absorb longer wavelengths. Studies of the Maillard reaction have shown that complex products containing cyclic polyenes and donor-acceptor groups are produced (Fayle and Gerrard, 2002b).

The development of colour below fibre saturation point at a similar rate to colour development above fibre saturation point suggests that the majority of colour development is occurring in the cell walls. This is because the only water in the wood below fibre saturation point is the bound water in the cell walls. Digital micrographs of stain layers do show that the majority of kiln brown stain is due to darkened cell walls (McCurdy et. al., 2005).

The rate measurement experiments show clearly that there is a non-linear relationship between temperature and the rate of colour development. This is to be expected for any chemical reaction, though in this case it was not possible to fit the data to the Arrhenius equation. This is likely to be due to there being more than one reaction involved in the formation of colour. Regardless of the reaction mechanism the rate of colour development increases greatly above $60^{\circ} \mathrm{C}$.

The experiments have shown that the smoothing of the surfaces of green wood samples with a plane has caused the kiln brown stain to form closer to the surface where it has been successfully measured using a reflectance spectrophotometer.

In normal rough-sawn timber the evaporative front recedes through the layer of damaged tracheids at the surface early in drying forming what is known as the thin dry layer (McCurdy and Keey, 2002). This means that most colour development occurs at 1 to $2 \mathrm{~mm}$ below the surface and is not always apparent on the surface. The process of removing the damaged layer means that the evaporative front stays at the surface and the formation of colour is more obvious and can be measured non-destructively during the drying process.

This technique for measuring the development of colour in wood during drying shows potential to be a useful research tool and results from initial experiments show that further research is warranted and should yield useful and interesting results. In particular the formation of kiln brown stain below fibre saturation point is significant for the design of schedules to combat the formation of such discolouration. 


\section{CONCLUSIONS}

The results presented here have shown that surface colour formation can be measured during drying if the surface is planed in the green state. Using this method the experiments performed have measured the rate of colour formation between $50^{\circ} \mathrm{C}$ and $70^{\circ} \mathrm{C}$ and shown that the rate is greatly increased above $60^{\circ} \mathrm{C}$. The experiments have also shown that colour formation occurs both above and below the fibre saturation and the moisture content has little effect on the rate of colour formation.

\section{REFERENCES}

Dawson, B.; Riley, S.; Cown, D. 2003. Colour measurements of wood. Wood Processing Newsletter, Issue \#23, NZFRI.

Dieste, A. 2002. Colour development in Pinus radiata D. Don under kiln-drying conditions. ME thesis, Department of Chemical and Process Engineering, University of Canterbury, New Zealand.

Fayle, S.E.; Gerrard, J.A. 2002a. What is the Maillard reaction? In: The Maillard Reaction. RSC Food Analysis Monographs, Royal Society of Chemistry, Cambridge, UK.

Fayle, S.E.; Gerrard, J.A. 2002b. New methodologies, new approaches In:

The Maillard Reaction. RSC Food Analysis Monographs, Royal Society of Chemistry, Cambridge, UK.

Kreber, B.; Haslett, A. N. 1997. A study of some factors promoting kiln brown stain formation in radiata pine. Holz als Roh und Werkstoff 55 (4): 215-220.

Ledig, S. F.; Seyfarth, R. 2001. Characterization of surface color during wood processing. Proceedings of the $7^{\text {th }}$ International IUFRO Wood Drying Conference, Tsukuba, Japan: 288-293.

McCurdy, M.C.; Nijdam, J.J.; Keey, R.B. 2001. Biological control of kiln brown stain in radiata pine. Proceedings of the $7^{\text {th }}$ International IUFRO Wood Drying Conference, Tsukuba, Japan.

McCurdy, M.C.; Keey, R.B. 2002. The nature of the surface zone of softwood sapwood during kiln drying. Proceedings of the $9^{\text {th }}$ APCChE Congress and CHEMECA 2002, Christchurch, NZ.

McCurdy, M.C.; Pang, S.; Keey, R.B. 2003. Measurement of colour development in Pinus radiata sapwood boards during drying at various schedules. Proceedings of the $8^{\text {th }}$ International IUFRO Wood Drying Conference, Brasov, Rumania.

McCurdy, M.C.; Pang, S.; Keey, R.B. 2005. Microscopic observation and image analysis of kiln brown stain layers in Pinus radiata boards. Proceedings of the Joint Conference of SCENZ/ FEANZ, Christchurch, New Zealand.

McDonald, A. G.; Fernandez, M.; Kreber, B.; Laytner, F. 2000. The chemical nature of kiln brown stain in radiata pine. Holzforschung 54 (1): 12-22. 
Nassau, K. 2001. The physics and chemistry of color: the fifteen causes of color (2 ${ }^{\text {nd }}$ Edition). John Wiley \& Sons, Inc. New York.

Pang, S.; Langrish, T.A.G.; Keey, R.B. 1994. Moisture movement in softwood timber at elevated temperatures. Drying Technology 12(8): 1897-1914. 